\title{
Comparison between PCA analysis and Grey based Taguchi analysis of TIG welding process parameters on Duplex stainless steel
}

\author{
Sandip Mondal 1,", Goutam Nandi ${ }^{2}$, Pradip Kumar Pal ${ }^{2}$ \\ ${ }^{1}$ Department of Mechanical Engineering, Haldia Institute of Technology, Haldia 721657, India \\ 2 Department of Mechanical Engineering, Jadavpur University, Kolkata-700032, India \\ ${ }^{*}$ Corresponding authors email: sandip mondal2004@rediffmail.com \\ DOI: https://doi.org/10.34256/irjmt2148 \\ Received: 03-06-2021, Revised: 04-07-2021, Accepted: 08-07-2021, Published: 09-07-2021
}

Abstract: Tungsten inert gas (TIG) welding on Duplex stainless steel (DSS) is more easy, comfortable and useful, if the process is precisely understood and controlled through development of the science \& technology. TIG welding on DSS has been performed with the help of specific controlled welding process parameters. Welding quality has been strongly depended on these process parameters. In this study, some valuable welding parameters are chosen. These are welding current, shielding gas flow rate and speed of welding. These process parameters of TIG welding for ASTM/UNS 2205 DSS welds are optimized by using Principal Component Analysis (PCA) method and Grey based Taguchi's L9 Orthogonal array (OA) experimental plan with the conception of signal to noise ratio $(\mathrm{N} / \mathrm{S})$. After that, compression results of above mentioned two analyses of TIG welding process parameters have been calculated. The quality of the TIG welding on DSS has been evaluated in term of ultimate tensile strength, yield strength and percentage of elongation. Compression results of both analyses indicate application feasibility for continuous improvement of welding quality on DSS in different components of chemical, oil and gas industries.

Keywords: TIG welding, UNS DSS2205, Principal Component Analysis (PCA) method, Grey based Taguchi analysis

\section{Introduction}

The exceptional blend of double phase configuration of ferrite with austenite has been seen in DSS. Austenite structure provides a unique arrangement of strength as well as resistance to corrosion. Ferrite structure provides local corrosion resistance for Duplex stainless steel. Deference type of welding techniques like Gas metal arc welding (GMAW), Manual metal arc welding (MMAW), Submerged arc welding (SAW) can use to coalesce DSS plates. But, TIG welding on DSS is more easy, comfortable and less costly.

Some remarkable researchers have been investigated regarding TIG welding, welding on Duplex stainless steel, or related subject matter. They have been established their opinion authentically. Lakshminarayanan et al. established that the joints welded by GTAW technique shows superior tensile strength values and higher impact strength values [1]. Magudeeswaran et al. investigated on the predominant factor in the electrode gap which affects the characteristic relation of DSS welds welded by a TIG welding method [2]. Badjia et al. observed as in the received metal the textures of both phases are mixtures of recrystallization textures and deformation, which generally establish between the material of single phase BCC and FCC structure [3,4]. Tarng and Yang applied Taguchi technique to optimized weld bead geometry in GTAW [5]. Tarng et al. also investigated on grey-based Taguchi technique to decide optimal procedure factors for SAW in hard facing with concern of several welding characteristics [6, 7]. Different common approaches have been used by various researchers to solve welding related optimization problem in such as response surface methodology, Taguchi technique, multi regression analysis etc [8-11]. TIG welding has been done to get high quality welds in aluminium, stainless steels, nicrome alloys (80/20 nickel- chromium) and copper for use in oil and chemical plants [12]. The Taguchi technique is the most accepted method to solve the optimization difficulties within the area of manufacturing technology $[6,10]$. The process uses a sensible investigational design said orthogonal array design with signal to noise ratio $(\mathrm{S} / \mathrm{N}$ ratio). Del Coz Diaz et al. showed the significant role of material characteristics of dissimilar stainless steels 
using finite element technique with the birth and death procedure [13]. ul-Haq et al. researched on textures and microstructures of duplex stainless steel [14]. They also showed the rolling texture development in the micro-structure of duplex stainless steel. Palani and Murugan investigated the cladding effect on weld bead geometry using different factors, like current, welding speed, nozzle-to-plate distance at the time of welding [15].

In current study, it is planned to decide the most excellent procedure conditions in TIG welding on DSS to get preferred yield strength, percentage of elongation and ultimate tensile strength comparing between deferent optimization results which comes out from deferent optimization of TIG welding on DSS process optimization analysis. Process optimization is performed with the help of Grey-based Taguchi method for evaluation of multi-response optimization problem and Principal Component Analysis (PCA) method.

Duplex stainless steel (UNS2205) sheets of dimensions $75 \mathrm{~mm} \times 50 \mathrm{~mm} \times 3 \mathrm{~mm}$ are welded by TIG welding process. No filler wire is used for welding. Argon is used as the shielding gas for protection of welding zone, base metal and Tungsten electrode from atmospheric reaction. The effects of TIG welding procedure factors like current, gas flow rate and welding speed on ultimate tensile strengths of butt- welded joints of ASTM/UNS 2205 DSS have been studied. The parameters of TIG welding have been optimized by Grey based Taguchi technique and also by Principal Component Analysis (PCA) method using MINITAB 16. After that both optimized results has been compared to determine the optimum parametric setting. Dimensions of each Duplex stainless steel plate are shown in Figure 1.

\section{Experimental work}

Duplex Stainless Steel (ASTM/UNS: 2205) material is used as the base metal for experimental work. Welding arrangement has been ready to perform TIG welding process. DSS plates have been welded with suitable welding factors like current, welding speed, gas flow rate. The experiments are completed with a designed investigational way which is L9 orthogonal array design of Taguchi method. Finally both optimized results have been compared to evaluate the optimal TIG welding process parameters. TIG welding on DSS has been completed by 3 levels of welding current, 3 levels of shielding gas flow rate, 3 levels of speed of welding.

Chemical composition of this base metal has been exhibited here by Table 1 . Welding process factors with their levels have been listed within Table 2.

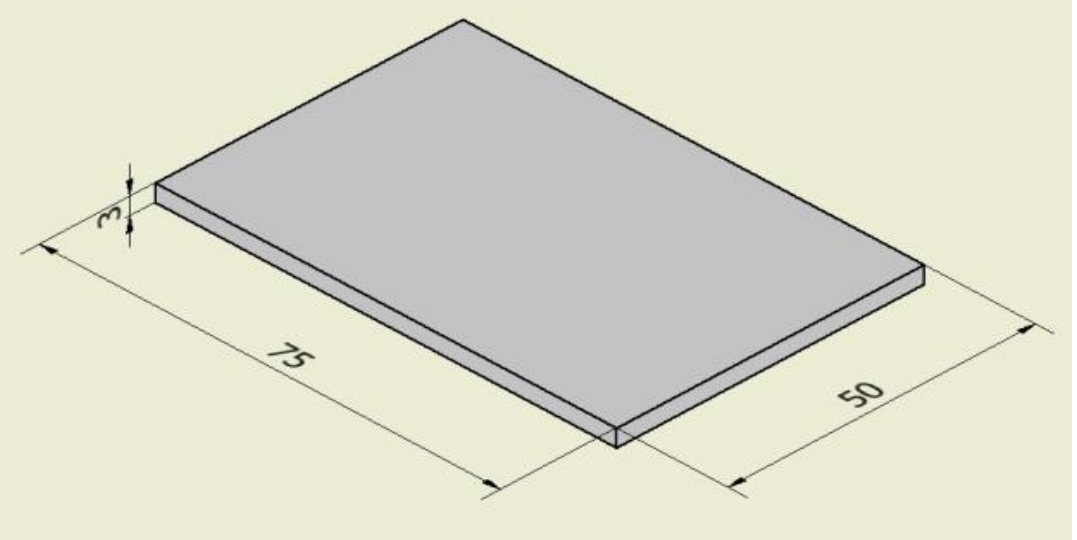

Figure 1. Dimensions of each sheet

Table 1. Composition of DSS

\begin{tabular}{|l|l|l|l|l|l|l|l|l|l|}
\hline & $\mathrm{C}$ & $\mathrm{Mn}$ & $\mathrm{Si}$ & $\mathrm{P}$ & $\mathrm{Cr}$ & $\mathrm{S}$ & $\mathrm{Mo}$ & $\mathrm{Al}$ & $\mathrm{Ni}$ \\
\cline { 2 - 11 } Composition of elements in \% & 0.0210 & 1.7200 & 0.2800 & 0.0220 & 22.6500 & 0.0140 & 3.1800 & 0.0100 & 4.7300 \\
\cline { 2 - 11 } & $\mathrm{Co}$ & $\mathrm{Nb}$ & $\mathrm{Cu}$ & $\mathrm{Ti}$ & $\mathrm{Pb}$ & $\mathrm{V}$ & $\mathrm{Fe}$ & $\mathrm{N}$ & \\
\cline { 2 - 11 } & 0.0780 & 0.0400 & 0.0090 & 0.0080 & 0.0030 & 0.0110 & 67.123 & 0.1010 & \\
\hline
\end{tabular}


Table 2 Welding process factors with their levels

\begin{tabular}{|l|l|l|l|l|l|}
\hline Factors & Units & Notations & \multicolumn{3}{|l|}{ Levels } \\
\cline { 4 - 7 } & & & 1 & 2 & 3 \\
\hline Welding Current & $\mathrm{A}$ & $\mathrm{C}$ & 80 & 85 & 90 \\
\hline Gas Flow Rate & $\mathrm{I} / \mathrm{min}$ & $\mathrm{F}$ & 7 & 7.5 & 8 \\
\hline Speed of Welding & $\mathrm{mm} / \mathrm{s}$ & $\mathrm{S}$ & 2.3 & 2.8 & 3.5 \\
\hline
\end{tabular}

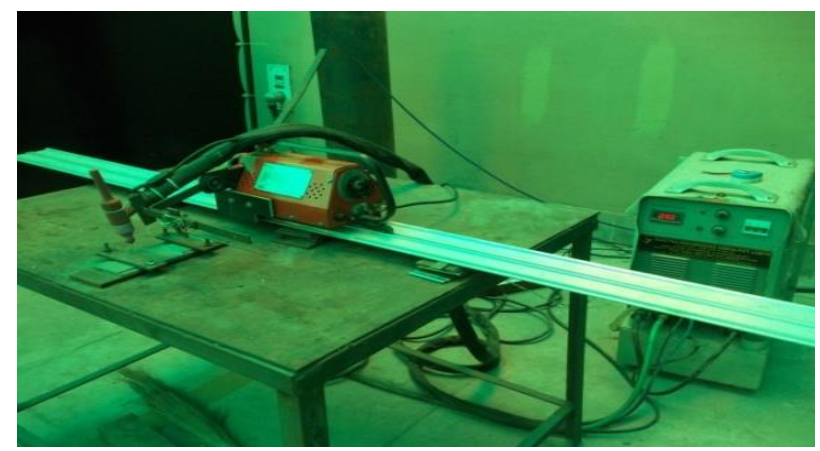

Figure 2. Photographic view of TIG welding equipments arrangement
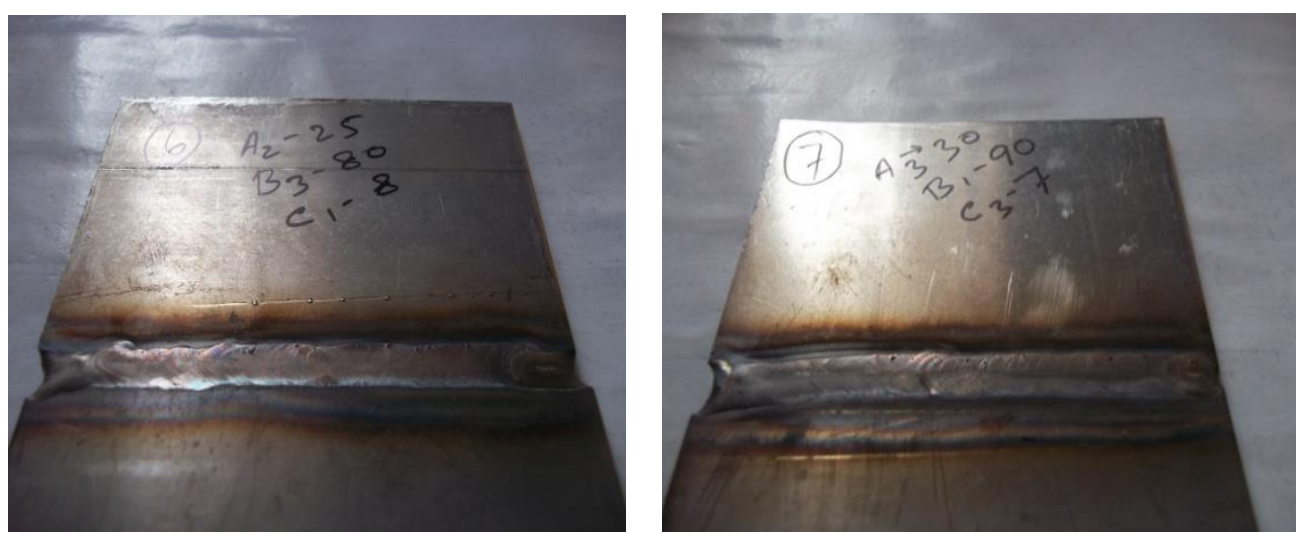

Figure 3. Photographic observation of welding sample no $6 \& 7$

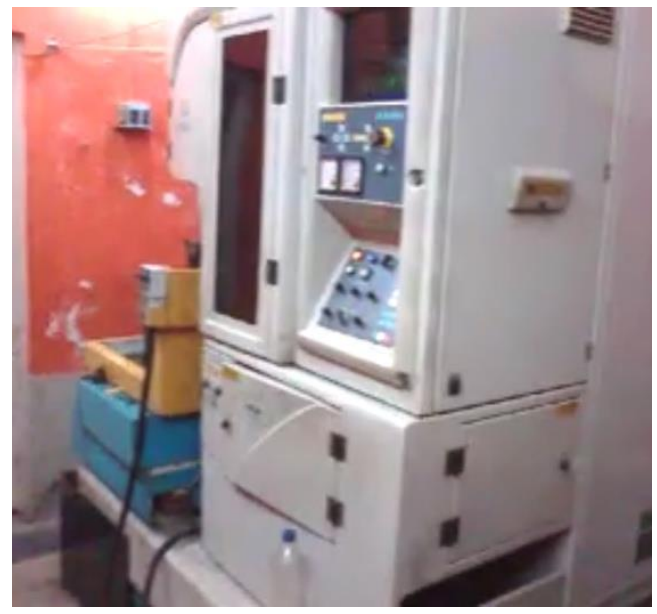

Figure 4. Photographic view of WEDM

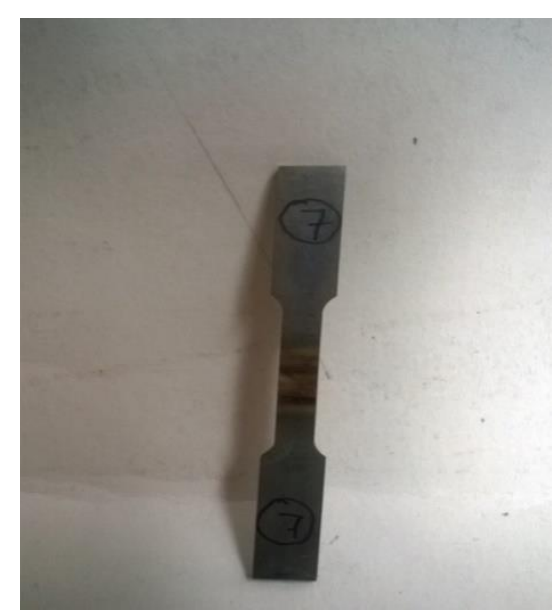

Figure 5. Photographic view of tensile sample no.7 


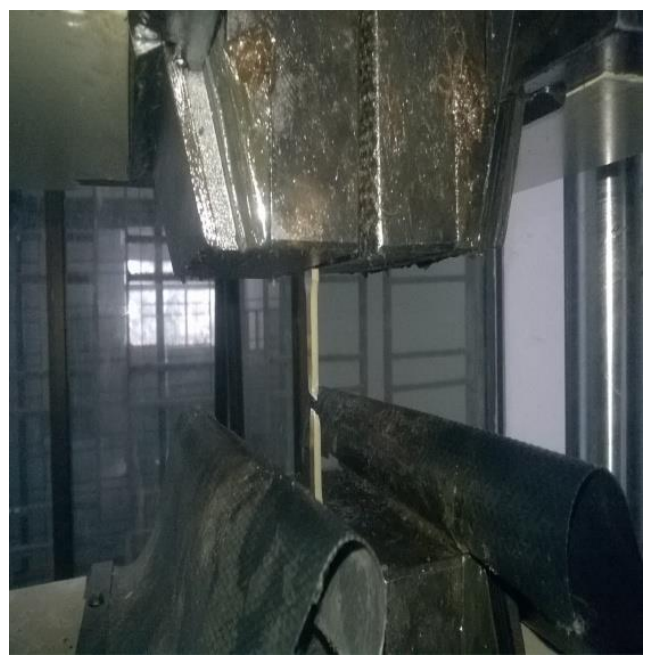

Figure 6. Photographic view of tensile testing machine after testing

Table 3 Tensile test results

\begin{tabular}{|c|c|c|c|}
\hline Sample No. & Yield Strength (MPa) & Ultimate Tensile Strength (MPa) & Percentage of Elongation (\%) \\
\hline 1 & 183.3 & 460 & 10.4530 \\
\hline 2 & 236.7 & 595 & 11.6650 \\
\hline 3 & 253.3 & 635 & 17.7770 \\
\hline 4 & 243.3 & 610 & 14.9470 \\
\hline 5 & 260 & 645 & 14.9070 \\
\hline 6 & 253.3 & 630 & 11.9810 \\
\hline 7 & 256.7 & 640 & 14.0340 \\
\hline 8 & 243.3 & 610 & 10.9380 \\
\hline 9 & 260 & 650 & 14.4790 \\
\hline
\end{tabular}

Table 4. Grey relational grades

\begin{tabular}{|l|l|}
\hline Experiment no. & Grey relational grade \\
\hline 1 & 0.333333 \\
\hline 2 & 0.543353 \\
\hline 3 & 0.905548 \\
\hline 4 & 0.654808 \\
\hline 5 & 0.836875 \\
\hline 6 & 0.68876 \\
\hline 7 & 0.773353 \\
\hline 8 & 0.583024 \\
\hline 9 & 0.84205 \\
\hline
\end{tabular}




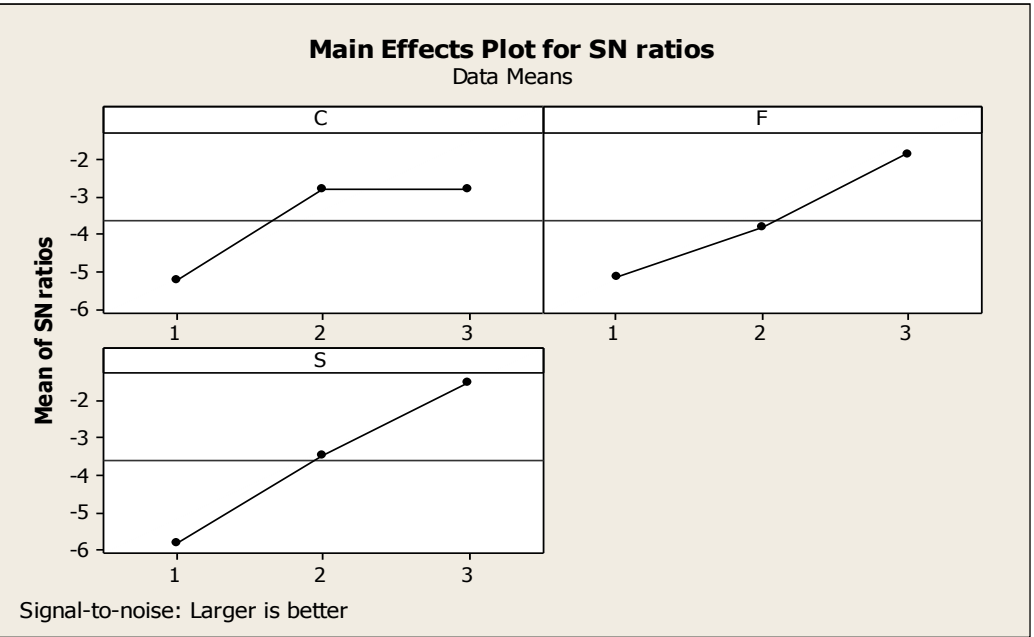

Figure 7. Main effect plot for $\mathrm{SN}$ ratios

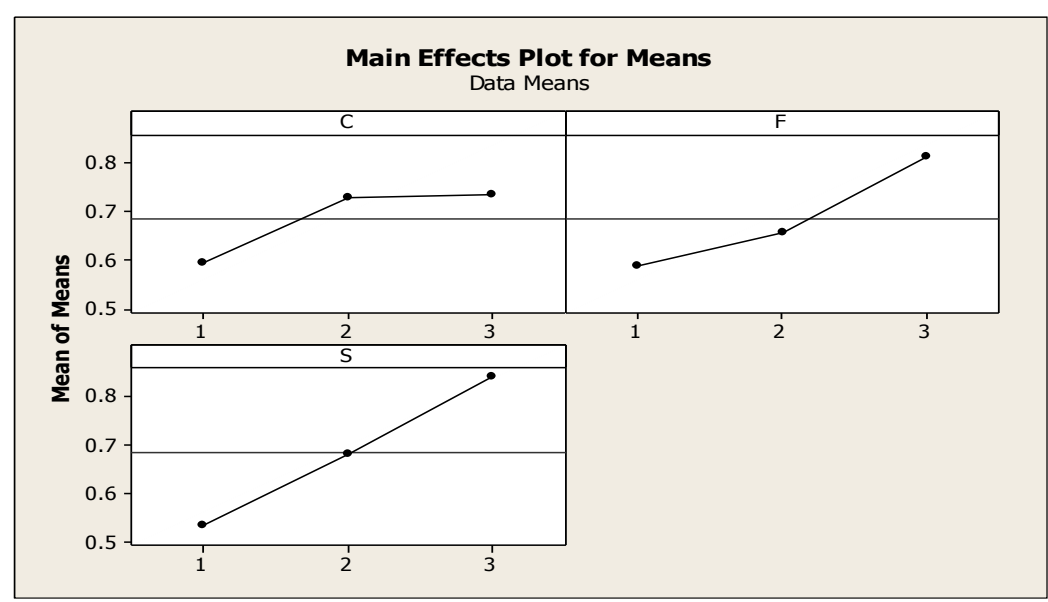

Figure 8. Main effect plot for means

\begin{tabular}{|c|c|c|c|}
\hline \multicolumn{4}{|c|}{ Table 5. Eigen analysis of the correlation matrix } \\
\hline \multirow{2}{*}{ Variables } & \multicolumn{3}{|c|}{ Eigen vectors } \\
\cline { 2 - 4 } & PC1 & PC2 & PC3 \\
\hline S/N-YS & 0.611 & -0.358 & 0.706 \\
\hline S/N-UTS & 0.611 & -0.354 & -0.708 \\
\hline S/N-PE & 0.503 & 0.864 & 0.003 \\
\hline
\end{tabular}

\begin{tabular}{|c|c|c|c|}
\hline & $(\xi 1)$ & $(\xi 2)$ & $(\xi 3)$ \\
\hline Eigen value & 0.611 & 0.4862 & 0.0007 \\
\hline AP & 0.838 & 0.162 & 0.000 \\
\hline CAP & 0.838 & 1.000 & 1.000 \\
\hline
\end{tabular}


Table 6. Principal component and calculated MPI

\begin{tabular}{|l|l|l|l|l|}
\hline SI. no. & SN-Yield strength & SN-Ultimate tensile strength & SN- Percentage of elongation & Calculated MPI \\
\hline 1 & 45.2632 & 53.2552 & 20.3848 & 46.5571 \\
\hline 2 & 47.484 & 55.4903 & 21.3377 & 48.7810 \\
\hline 3 & 48.0727 & 56.0555 & 24.9972 & 49.3659 \\
\hline 4 & 47.7228 & 55.7066 & 23.4911 & 49.0162 \\
\hline 5 & 48.2995 & 56.1912 & 23.4678 & 49.5780 \\
\hline 6 & 48.0727 & 55.9868 & 21.5699 & 49.3548 \\
\hline 7 & 48.1885 & 56.1236 & 22.9436 & 49.4740 \\
\hline 8 & 47.7228 & 55.7066 & 20.7788 & 49.0162 \\
\hline 9 & 48.2995 & 56.2583 & 23.2148 & 49.5888 \\
\hline
\end{tabular}

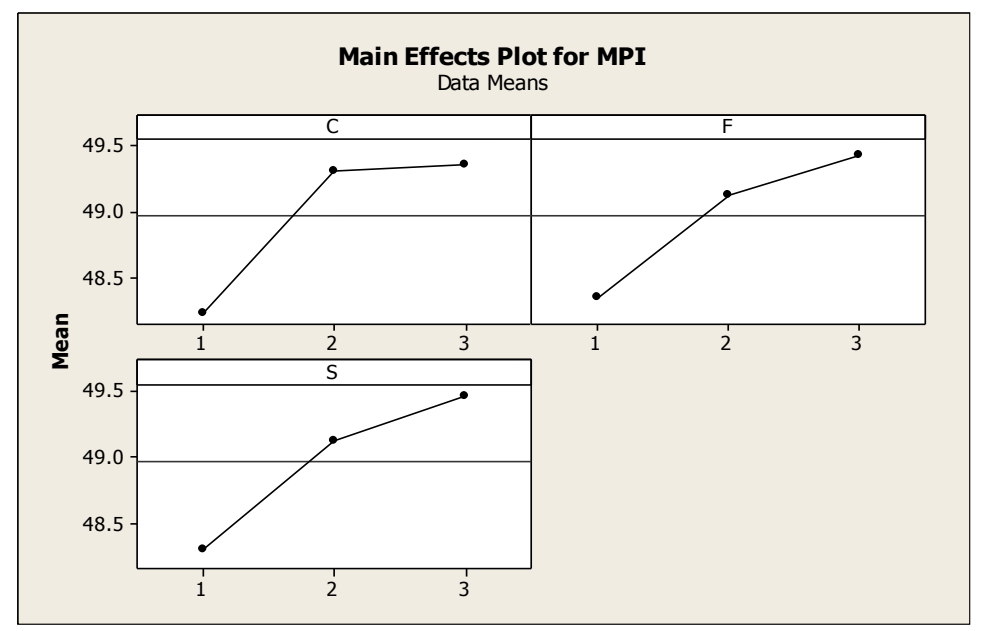

Figure 9. Main Effect plots of the MPI ( $\mathrm{S} / \mathrm{N}$ ratio)

9 butt joint TIG welded samples have been created employing 3 levels of current, 3 level of speed of welding and 3 levels of shielding gas flow rate to determine the effects of ultimate tensile strength, yield strength and percentage of elongation. The photographical view of TIG welding equipments arrangement has been showing by Figure 2 .

After completed the TIG welding of DSS plates, the Photographic observation of welded sample no 6 \& 7 has been shown in Figure 3.

Tensile testing samples are created from the TIG welding plates, by Electronica Sprintcut-734 WEDM (Input power supply 3 Phase, AC 415 V, $50 \mathrm{~Hz}$, linked load $15 \mathrm{KVA}$ ) wire cutting machining. A photographic view of WEDM is exposed by Figure 4 . Photographic view of tensile sample of welding specimen no.7 out of nine samples has been shown in Figure 5 . Then, these samples have been tested by tensile testing machine.

These tensile samples have been tested with the help of tensile testing machine to determine the tensile strength, percentage of elongation and yield strength. Every tensile testing result is collected properly. Photographic view of tensile testing machine after testing the tensile sample is shown in Figure no.6. And tensile testing results are also plotted in tabular form in Table 3.

\subsection{Optimization by Grey Taguchi method}

TIG welding process parameters have been optimized using Grey-Taguchi method. Normalized 
investigational results have been transferred into grey relational co-efficient of every quality characteristics. Then, grey relational co-efficient for every response have been collected to evaluate Grey relational grade. Larger result of grey relational grade with equivalent to factor arrangement has been understood to be nearer of the optimal. Grey relational grades have been plotted by tabular form in Table 4.

Signal to noise ratio and Main effect plot for means have been shown in Figure $7 \& 8$ respectively. Using this figures, optimal factor arrangement has been calculated by considering higher the better principle. The optimal parameter setting evaluates C3, F3 and S3 which means current is $90 \mathrm{~A}$, gas flow rate is $8 \mathrm{I} / \mathrm{min}$ and speed of welding is $3.5 \mathrm{~mm} / \mathrm{s}$.

\subsection{Optimization by Principal Component Analysis}

The experimental results of yield strength, ultimate tensile strength and percentage of elongation are converted into $\mathrm{S} / \mathrm{N}$ ratio for analysis using $\mathrm{PCA}$ method. After normalization of results, verification is completed whether responses are correlated or not, by Minitab.

Then, the Eigen value, Eigen vector, accountability proportion (AP) and cumulative accountability proportion (CAP) are calculated. Eigen analysis of the correlation matrix is given in Table 5.

The Multi-response Performance Index (MPI) is calculated by the equation $\mathrm{MPI}=\xi 1^{*} 0.838+\xi 2^{*} 0.162+$ $\xi 3^{*} 0.000$. The MPI results are considered as the single objective function. These are optimised to get the optimum result.

The factorial arrangement so as to maximized MPI has been treated as optimal parametric arrangement ensuring better quality of weld. Principal Components and evaluated MPI have been presented in Table 6. S/N ratio plot of MPI have been presented in Figure 9. $\mathrm{S} / \mathrm{N}$ ratio has been evaluated with the help of Higher-the-Better (HB) principle. From Main Effect plots of the MPI (S/N ratio), the optimal parameter setting becomes $\mathrm{C} 3, \mathrm{~F} 3$, S3 which means current is 90 A, gas flow rate is $8 \mathrm{l} / \mathrm{min}$ and speed of welding is 3.5 $\mathrm{mm} / \mathrm{s}$. Ultimately quality has developed with the help of this optimal setting.

\section{Compression between optimization of Grey Taguchi method and PCA method}

The tensile testing results have been optimized with the help of both techniques Grey Taguchi technique and Principal Component Analysis. Signal to noise ratio has been plotted with the help of optimization results which have been evaluated from above stated both techniques. In both cases same result has been observed that is the optimal parameter setting becomes $\mathrm{C} 3, \mathrm{~F} 3, \mathrm{~S} 3$ which means current is 90 A, gas flow rate is $8 \mathrm{I} / \mathrm{min}$ and speed of welding is 3.5 $\mathrm{mm} / \mathrm{s}$.

\section{Conclusions}

In this current study, complete methodology of Taguchi optimization procedure with Grey relational analysis and Principal Component Analysis has been accepted. It also utilized for calculating optimal parametric arrangement to reach satisfactory value of tensile strength, yield strength and percentage of elongation of TIG welding on Duplex stainless steel. Welding process factors like current, shielding gas flow rate, speed of welding played an important role in mechanical properties of TIG weld like yield strength, ultimate tensile strength and percentage of elongation. Here, both analyzed optimized values are compared. The same result in both cases has been observed. Taguchi's $\mathrm{S} / \mathrm{N}$ ratio theory has been employed to establish the optimum situation on behalf of maximum ultimate tensile strength, yield strength and percentage of elongation. The optimal parameter combination becomes C3, F3, S3 i.e. welding current is $90 \mathrm{~A}$, gas flow rate is $8 \mathrm{l} / / \mathrm{min}$ and speed of welding is $3.5 \mathrm{~mm} / \mathrm{s}$.

\section{References}

[1] AK. Lakshminarayanan, K. Shanmugam, V. Balasubramanian, Effect of Welding Processes on Tensile and Impact Properties, Hardness and Microstructure of AISI 409M Ferritic Stainless Joints Fabricated by Duplex Stainless Steel Filler Metal, Journal of Iron and Steel Research, International, 16(2009) 66-72. [DOI]

[2] G. Magudeeswaran, S.R. Nair, L. Sundar, N. Harikannan, Optimization of process parameters of the activated tungsten inert gas welding for aspect ratio of UNS S32205 duplex stainless steel welds, Journal of Defense Technology, 10(2014) 251-260. [DOl]

[3] R. Badjia, B. Bacroix, M. Bouabdallah, Texture, microstructure and anisotropic properties in annealed2205 duplex stainless steel welds, Journal of Materials Characterization, 62(2011) 833-843. [DOI]

[4] S.C. Juang, Y.S. Tarng, Process parameters selection for optimizing the weld pool geometry in the tungsten inert gas welding of stainless 
steel, Journal of Materials Processing Technology, 122(2002) 33-37. [DOI]

[5] Y.S. Tarng, W.H. Yang, Optimization of the weld bead geometry in gas tungsten arc welding by the Taguchi method, International Journal of Advanced Manufacturing Technology, 14(1998) 549-554. [DOI]

[6] Y.S. Tarng, S.C. Juang, C.H. Chang, The use of grey-based Taguchi methods to determine sub merged arc welding process parameters in hard facing, Journal of Materials Processing Technology 128(2002) 1-6. [DOI]

[7] R. Yilmaz, H. Uzun, Mechanical properties of austenitic stainless steels welded by GMAW and GTAW, Journal of Marmara for Pure and Applied Sciences 18(2002) 97-113

[8] C. Drei, TMT. Stainless, (2014), Practical guidelines for the fabrication of duplex stainless steel, (3 $3^{\text {rd }}$ Edition), International molybdenum association (IMOA), London, UK

[9] S. Datta, A. Bandyopadhyay, P.K. Pal, Greybased taguchi method for optimization of bead geometry in submerged arc bead-on-plate welding, International Journal of Advanced Manufacturing Technology, 39(2007) 11361143. [DOI]

[10] H. Rowlands, J. Antony, G. Knowles, An application of experimental design for process optimization. The TQM Magazine 12(2000) 7883. [DOI]

[11] S.H. Lim, C.M. Lee, W.J. Chung, A study of the optimal cutting condition of a high speed feeding type laser cutting machine by using Taguchi method, International Journal of Precision Engineering and manufacturing, 7(2006) 18-23.

[12] R.S. Parmar, (2003) Welding engineering and technology, $2^{\text {nd }}$ edition, Khanna Publishers, New Delhi.

[13] J.J. Del Coz Díaz, P.M. Rodríguez, P.J.G. Nieto, D. Castro-Fresno, Comparative analysis of TIG welding distortions between austenitic and duplex stainless steels by FEM, Journal of Applied Thermal Engineering, 30(2010) 24482459.

[14] A. ul-Haq, H. Weiland, J.H. Bunge, Textures and microstructures in duplex stainless steel, Materials Science and Technology, 10(1994) 289-298. [DOl]

\section{[15]}

P.K. Palani, N. Murugan, Sensitivity Analysis for Process Parameters in Cladding of Stainless Steel by Flux Cored Arc Welding, Journal of Manufacturing Processes, 8/2(2006) 90-100. [DOI]

\section{Funding}

No funding was received for conducting this study.

\section{Conflict of interest}

The authors have no conflicts of interest to declare that they are relevant to the content of this article.

\section{About the License}

(C) The author(s) 2021. The text of this article is open access and licensed under a Creative Commons Attribution 4.0 International License 